\title{
Polygyny and extra-pair paternity enhance the opportunity for sexual selection in blue tits
}

\author{
Oscar Vedder • Jan Komdeur • Marco van der Velde • \\ Elske Schut • Michael J. L. Magrath
}

Received: 26 July 2010 /Revised: 26 July 2010 / Accepted: 4 October 2010 /Published online: 30 October 2010

(C) The Author(s) 2010. This article is published with open access at Springerlink.com

\begin{abstract}
Polygyny and extra-pair paternity are generally thought to enhance sexual selection. However, the extent to which these phenomena increase variance in male reproductive success will depend on the covariance between success at these two strategies. We analysed these patterns over four breeding seasons in facultatively polygynous blue tits Cyanistes caeruleus. We found that both polygyny and extra-pair paternity increased variance in male reproductive success and that standardised variance in annual number of genetic fledglings was 2.6 times higher than standardised variance in apparent success when assuming strict monogamy. Nevertheless, male success at securing within-pair paternity was unrelated to success at gaining extra-pair paternity and, when considering the positive effect of age on extra-pair success and attracting a second female, polygynous males were no more likely to sire extra-pair fledglings. Overall, polygynous males fledged more genetic offspring than monogamous males, but first-year polygynous males lost a greater share of within-pair paternity. A literature review suggests that this adverse effect of polygyny on within-pair paternity is frequent among birds, inconsistent with the prediction that females engage in extra-pair copulation with successful males to obtain good genes. Furthermore, a male's share of paternity was repeatable between years, and
\end{abstract}

Communicated by S. Pruett-Jones

O. Vedder $(\bowtie) \cdot$ J. Komdeur $\cdot$ M. van der Velde $\cdot$ E. Schut $\cdot$

M. J. L. Magrath

Animal Ecology Group, Centre for Ecological and Evolutionary

Studies, University of Groningen,

P.O. Box 14, 9750 AA Haren, The Netherlands

e-mail: o.h.vedder@rug.nl

M. J. L. Magrath

Department of Wildlife Conservation and Science, Zoos Victoria,

P.O. Box 74, Parkville, Victoria 3052, Australia among females of polygynous males within years, such that a compatibility function of extra-pair copulations was likewise unsupported. Instead, we suggest that the observed patterns are most consistent with a fertility insurance role for extra-pair copulations, which does not exclude the greater opportunity for sexual selection through differential ability of males to gain paternity.

Keywords Compatible genes · Extra-pair fertilisations . Female choice $\cdot$ Male-male competition $\cdot$ Mating system . Sperm competition

\section{Introduction}

The potential for sexual selection increases with the degree of variation in mating success between individuals in a population (e.g. Wade and Arnold 1980). In socially monogamous species, variance in male mating success may be limited to variation in fecundity between the females they pair with (Kirkpatrick et al. 1990). However, even among socially monogamous species, sexual dimorphism is common, suggesting the operation of strong sexual selection. In many socially monogamous bird species, for example, males are larger and more colourful, indicating that variance in male mating success may be considerably greater than among females. One potential source of this additional variance in male mating success is extra-pair fertilisation (Moller and Birkhead 1994; Owens and Hartley 1998), which occurs commonly among many species of birds (Griffith et al. 2002). However, few studies have investigated the extent to which extra-pair paternity (EPP) may increase variance in male reproductive success and the findings appear to vary considerably between studies (Freeman-Gallant et al. 2005; Whittingham and Dunn 2005). This variation may be 
explained by differences in absolute rates of EPP but also by differences in the direction of covariance between males gaining EPP at other nests and retaining within-pair paternity (WPP) at their own nest (e.g. Webster et al. 1995; Sheldon and Ellegren 1999; Freeman-Gallant et al. 2005).

Understanding patterns of covariance between the gain and loss of paternity may also help clarify why females engage in extra-pair copulations (EPC). Although avoiding costs of male coercion has been proposed as an explanation for female engagement in EPC (Westneat and Stewart 2003; Arnqvist and Kirkpatrick 2005), the observation that females, in many species, actively seek or participate in EPC (e.g. Kempenaers et al. 1992; Gray 1996; Double and Cockburn 2000) suggests that benefits to the female are likely in most cases. Potential benefits include increased offspring quality by mating with males of higher genetic quality ('good genes') or compatibility ('compatible genes') than the social male (Jennions and Petrie 2000; Neff and Pitcher 2005), or insurance against functional infertility of the social male (Sheldon 1994). Patterns of covariance between paternity gains and losses may be very much influenced by the underlying explanation for female engagement in EPC and the effectiveness of male strategies to secure paternity with their social female (e.g. mate guarding) (Kokko and Morrell 2005). If most females favour particular males for EPC, these males may benefit from pursuing EPC at the expense of mate guarding (Chuang-Dobbs et al. 2001). In this case, covariance between gaining and losing paternity will depend on the extent to which the male's attractiveness compensates for potential loss of WPP owing to reduced mate guarding (Kokko and Morrell 2005), which may be negligible if female motivation for EPC is driven mainly by fertility insurance or a 'compatible genes' function.

In facultatively polygynous species, the variation between males in success at acquiring extra social females may also contribute to male variance in reproductive success. However, the strategy of attracting additional social mates may not be independent of behaviours or traits associated with gaining EPP or limiting WPP loss, leading to further covariances between reproductive strategies. For example, the male tradeoff between mate guarding and pursuing EPC (described above) may be particularly pronounced in polygynous males as they attempt to secure paternity with more than one female. On the other hand, the original 'sexy son' hypothesis postulates that females should prefer polygynous males because their sons will inherit the qualities of their fathers that enable them to attract multiple mates (Weatherhead and Robertson 1979). Hence, polygynous males may be predicted to lose less WPP and gain more EPP than monogamous males. Perhaps unsurprisingly, empirical studies on facultatively polygynous species have reported the full spectrum of relationships between the proportion of WPP and male mating status (e.g. Dunn and Robertson 1993; Freeland et al. 1995; Freeman-Gallant 1997; Soukup and Thompson 1997). However, few studies have explicitly reported whether among polygynous males the proportion of WPP is correlated among their multiple female social partners (Smith and Vonschantz 1993). This pattern would be revealing as 'good genes' or fertility insurance scenarios would predict poor-quality males to have low levels of WPP with all mates, while, under the compatibility scenario, paternity share should vary with female identity. Here, we analyse these relationships in blue tits (Cyanistes caeruleus).

Blue tits generally breed as monogamous pairs, but a small proportion of males increase their apparent reproductive success considerably by attracting an extra social female in their territory (Dhondt et al. 1983; Dhondt 1987; Kempenaers 1994). They are a model species for the study of sexual selection and EPP in the wild (e.g. Kempenaers et al. 1992; Foerster et al. 2003; Charmantier et al. 2004; Magrath et al. 2009) and are moderately sexually dimorphic, with males being on average about 5\% larger in size than females (Cramp and Perrins 1993) and having more reflective plumage in the ultraviolet part of the colour spectrum (e.g. Hunt et al. 1998). EPP is common, typically occurring in over $40 \%$ of broods (e.g. Kempenaers et al. 1997; Leech et al. 2001; Charmantier et al. 2004; Magrath et al. 2009), and has been associated with male age (Kempenaers et al. 1997; Delhey et al. 2007b) and size (Kempenaers et al. 1997; Foerster et al. 2003) in some populations, but not in others (Krokene et al. 1998; Charmantier et al. 2004). Furthermore, extra-pair offspring have been found to be larger and heavier at fledging (Kempenaers et al. 1997; Dreiss et al. 2008) and more likely to fledge (Kempenaers et al. 1997; Charmantier et al. 2004) than their within-pair half-siblings, all favouring a genetic benefits explanation for female engagement in EPC. However, these disparities between extra-pair and within-pair offspring may instead be explained by nongenetic, maternal effects, as extra-pair offspring are positioned early in the laying and subsequent hatching order (Magrath et al. 2009), which may result from declining female motivation for EPC once laying commences, as expected under a fertility or compatibility insurance function (Vedder et al. 2010b). Indeed, offspring heterozygosity has been shown to increase when females engage in EPC with distantly breeding males (Foerster et al. 2003), thereby avoiding potential inbreeding depression (Kempenaers et al. 1996), especially as a fertilisation bias in favour of less related males is suggested (Foerster et al. 2006). Hence, it is unclear to what extent EPP in blue tits favours specific male traits through sexual selection. EPP has been estimated to increase the standardised variance in male reproductive success, compared to apparent success with the social female, by a factor of 1.7 (Kempenaers et al. 1992), which 
is low compared to several other bird species (FreemanGallant et al. 2005; Whittingham and Dunn 2005). Apart from a study by Kempenaers et al. (1995) that found that polygynous males do not lose more WPP, despite lower mate guarding intensity, surprisingly little has been reported about the effect of polygyny on the potential for sexual selection in blue tits.

Here, we use molecular genotyping to examine the effects of EPP (both losses and gains) and polygyny on variance in actual male reproductive success, as compared to variance in apparent success under strict monogamy. Furthermore, we explore how these different reproductive strategies are interrelated and evaluate how these relationships may shed light on the functional explanations for female engagement in extra-pair mating.

\section{Methods}

Study area and general procedures

The study was conducted over four consecutive breeding seasons (2006-2009) on a nestbox population at 'De Vosbergen' estate near Groningen in the north of the Netherlands $\left(53^{\circ} 08^{\prime} \mathrm{N}, 06^{\circ} 35^{\prime} \mathrm{E}\right)$. The area consists of 54 ha of mixed deciduous and coniferous forest interspersed with areas of open grassland and contains an excess of nestboxes designed especially for blue tits. Every breeding season (April-June), breeding activities were monitored from nest building to fledging.

In detail, all occupied nestboxes were checked daily during the nest building phase from the beginning of April to determine the start of laying. Nests were checked daily around the anticipated hatching date (following Vedder et al. 2010b) to determine the exact hatching date of the brood. Some clutches were collected just prior to hatching and hatched in incubators before being returned to their nest (as part of a different study; see Magrath et al. 2009), also providing accurate information on hatching date. Hatchlings were uniquely marked by clipping the very tip of one or two toenails in a specific combination, and a small blood sample (ca. $10 \mu \mathrm{l}$ ) was collected from the nestlings within 6 days of hatching. Nestlings were identified and banded at a brood age of 7-8 days. Parents were caught inside the nestbox when feeding nestlings 8-12 days after hatching. If a male was not caught at the first attempt, we continued to trap at the nest for several more days until we were confident that no male was feeding at the nest. At capture, adults were banded, sexed (based on the presence/absence of a brood patch), aged as 1 year or older (following Svensson 1992) and blood sampled for parentage analyses. The length of the tarsus was measured with a sliding calliper to the nearest $0.1 \mathrm{~mm}$, always by the same observer
(OV). Blood samples of parents and hatchlings were stored in $100 \%$ ethanol. Shortly before fledging, when broods were 15 days old, all surviving nestlings were identified and considered to have fledged.

\section{Molecular parentage analyses}

DNA was extracted from both parent and nestling blood samples using a chelex extraction method (Walsh et al. 1991). To exclude and assign paternity, parents and nestlings were genotyped for six microsatellite loci: Pca3, Pca7, Pca8 and Pca9 (Dawson et al. 2000), Pocc6 (Bensch et al. 1997) and Pdo5 (Griffith et al. 1999). For details on polymerase chain reactions (PCR) and determination of microsatellite allele sizes, see Magrath et al. (2009) for the years 2006-2007 and Vedder et al. (2010b) for the years 2008-2009.

Using Cervus 3.0 (Kalinowski et al. 2007), mean exclusion probability of the six markers was calculated to be 0.99934 for the first (female) parent and 0.99997 for the second (male) parent (given the genotype of the first parent). Maternity of the social female was confirmed by the microsatellite data for all but two nestlings (see Vedder et al. 2010a). By comparing the genotypes of each nestling with its social father, paternity of the social male was excluded, and the offspring assigned as extra-pair, if there were at least two mismatches between the genotype of the social father and offspring.

For all fledged extra-pair offspring and nestlings from nests where no feeding male was present, we attempted to assign paternity to one of all the breeding males sampled for that year, using Cervus. EPP was assigned when one of the sampled males matched all of the offspring's paternal alleles. Paternity was assigned for $75 \%$ of all identified extra-pair fledglings in the population.

\section{Data and definitions}

We omitted the males breeding in 2008 and/or 2009 that were subjected to experiments that resulted in reduced WPP (Vedder et al. 2010b) or an increase in the number of social fledglings (Vedder et al., unpublished results) from our analyses. Furthermore, we only included males that had at least one social fledgling, because otherwise, males who's nests failed late in the nestling phase would have a greater likelihood of inclusion in the data set compared to males that failed earlier in the nestling phase (before capture), potentially biasing our findings. This left 55 males for 2006, 54 males for 2007, 41 males for 2008 and 36 males for 2009. Eighteen males were included in 2 years and three males in 3 years. Hence, the data set consisted of 186 cases where we knew the annual genetic reproductive success (in terms of number of fledglings), for 162 individual males. Male age (first year or older) 
was always assigned, but in three cases, we did not measure the length of the tarsus.

Twenty-five $(15.4 \%)$ of these males were classified as polygynous. A male was classified as polygynous if he was caught at more than one nestbox (never at more than two, and always at a neighbouring nestbox, $n=17$ ), or if he sired the majority of nestlings in the nest of a neighbouring female that did not receive parental assistance from a male $(n=8)$. In those cases where a male was caught at two nests, the nest where laying commenced first and where the male was first caught (always the same nest) was classified as his primary nest. In those cases where the male was only caught at one nest, it was classified as his primary nest. No male was identified as being polygynous in more than one of the study years.

Although we identified two cases of conspecific brood parasitism in 2006 (Vedder et al. 2010a), we omitted these from our analyses as conspecific brood parasitism is extremely rare in nestbox-populations of blue tits (Vedder et al. 2007; Griffith et al. 2009) and, therefore, unlikely to contribute substantially to variance in reproductive success. Second broods were also excluded from analysis because there was only one successful second brood in the 4 years of the study.

The aim of this study was to evaluate different components of annual male reproductive success that reflect different reproductive strategies and assess how these components were interrelated. This also allowed us to compare how variance in actual (genetic) reproductive success compared to 'apparent' variance in reproductive success (assuming strict social and genetic monogamy). We partitioned annual male success into four components: (1) the number of fledglings produced with the only (or primary) social female - defined as the 'social' fledglings and reflecting the quality of a male's social female, territory quality and parental investment; (2) the proportion of these 'social' fledglings that the male actually sired - defined as proportion of within-pair paternity (WPP) and reflecting a male success at securing paternity; (3) the number of fledglings he sired with females that were paired to other males in the population-defined as number of extra-pair fledglings and reflecting a male's engagement in successful EPC and (4) the number of fledglings sired with a secondary female - defined as 'secondary' fledglings and reflecting a male's success at attracting, and securing paternity with, a second female. Among polygynous males, we distinguished between 'social' fledglings and 'secondary' fledglings because they reflect the outcome of potentially different reproductive strategies. Moreover, compared to 'social' fledglings, secondary fledglings usually receive little or no paternal care.

Annual genetic reproductive success was defined as the total number of fledglings produced in the study population in a given year that could be attributed genetically to a male (i.e. the number of genetic social offspring (which equates to number of social fledglings multiplied by the proportion of WPP), the number of extra-pair fledglings and the number of genetic secondary fledglings). 'Apparent' reproductive success was defined as the number of 'social' fledglings.

\section{Statistical analyses}

To compare variance in genetic vs 'apparent' reproductive success, the number of genetic fledglings and 'social' fledglings produced by individual males each year was standardised by dividing the variance by the squared mean (following Arnold and Wade 1984).

We used random intercept models, performed in MLwiN 2.02 (Rasbash et al. 2004), to examine the different components of annual genetic reproductive success (see above). These models included male identity as a random component to account for the non-independence of the multiple years of reproductive data available for some males. The percentage of variance in annual genetic reproductive success explained by each component was calculated by dividing the increase in unexplained random variance as each component term was removed separately from the full model (i.e. the model with all four components included as fixed effect) by the model predicted total random variance in annual genetic reproductive success (i.e. without fixed effects included).

We used regression analyses (again with male identity incorporated as random component) to assess the relationships between the four different components of reproductive success because bivariate correlation analyses could not correctly account for the distribution of the data. While causality could not be determined conclusively, we selected the component most likely to be influenced by the others as the dependent variable for these analyses. When the number of social fledglings was assigned as the dependent variable, we used a Poisson error distribution. When the proportion of WPP was assigned as the dependent variable, we used a binomial error distribution with a logit link function with the number of social fledglings as the denominator. Because the number of extra-pair fledglings followed an extremely skewed distribution $73 \%$ of males sired no extra-pair fledglings, $10 \%$ sired one, $5 \%$ sired two and $12 \%$ sired more than two, to a maximum of nine) this variable was also converted to a binary trait when analysed as a dependent variable (no extra-pair fledglings $=0$, one or more extra-pair fledgling $=1$; denominator $=1$ ). The number of secondary fledglings was converted to a binary variable, referred to as 'mating status' (monogamous $=0$ or polygynous $=1$; denominator $=1$ ), when used as either a dependent or independent variable, to most effectively distinguish polygyny as a separate reproductive strategy and allow for comparison with other studies. Because we 
were interested primarily in average relationships between components of male reproductive success, we combined the data from all four breeding seasons. However, we recognise that environmental effects may differ between years, acting on the occurrence and success of the different reproductive strategies independently. Hence, we tested for 'year-effects' by assigning year as a fixed categorical explanatory variable in each initial regression model. Additionally, male phenotypic characteristics that have been previously shown to influence the gain or loss of paternity in blue tits (i.e. tarsus length and age, see 'Introduction' section) were also included in initial models. Final models were derived through backwards elimination of non-significant terms. The significance (two-tailed) of all explanatory terms was determined using the Wald statistic, which approximates the $\chi^{2}$ distribution.

\section{Results}

Variance in annual genetic reproductive success

In $44 \%$ of broods, there was at least one fledgling that was not sired by the social male. Overall, $11 \%$ of all fledglings $(n=1693)$ were not sired by the social male. Standardised variance in male annual genetic reproductive success was 0.193 , which was 2.57 times greater than the standardised variance in apparent social reproductive success $(0.075$, $n=186$, Fig. 1). However, when the polygynous males
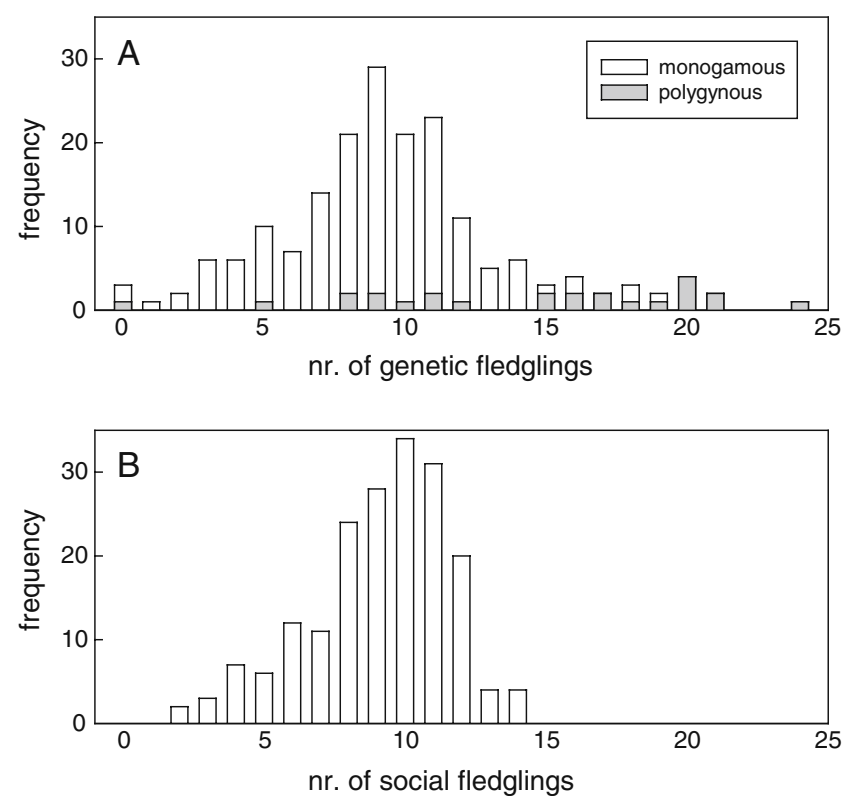

Fig. 1 Frequency distribution of a annual number of fledglings sired by monogamous and polygynous males in the study population and $\mathbf{b}$ apparent annual number of fledglings sired when assuming strict monogamy (i.e. number of fledglings with only the (primary) social female) were excluded, standardised variance in annual genetic reproductive success $(0.142)$ declined to 1.82 times the standardised variance in apparent social reproductive success $(0.078, n=161)$, suggesting that variation in mating status contributes substantially to the potential for sexual selection.

The four reproductive components (i.e. number of social fledglings, proportion of WPP, the number of sired extra-pair fledglings and the number of sired secondary fledglings) all contributed significantly to the mean and variance in male annual genetic reproductive success (Table 1). Note that the variance explained by all component terms when removed separately from the full model only accounted for $86.6 \%$ of the total variance (Table 1), indicating some degree of relatedness between these components.

Interrelatedness between reproductive components

To gain insight into the relationships between components of reproductive success, we first tested for effects of mating status, number of social fledglings and number of extra-pair fledglings on the proportion of WPP. To account for shared effects of year and male characteristics on multiple reproductive components, 'year' and male age and tarsus length were also included in the initial model. There was a random effect of male identity on the proportion of WPP (tested without fixed effects; $\chi^{2}=34.60, \mathrm{df}=1, p<0.001$ ). Only mating status remained in the final model, with polygynous males losing a greater proportion of WPP compared to monogamous males (Table 2a). There was no additional significant effect of the number of social fledglings, the number of extra-pair fledglings, year or age (Table 2a). Together with mating status in the model, there was a tendency for males with longer tarsi to sire a greater proportion of WPP (Table 2a). Overall, these results suggest that the lower proportion of WPP for polygynous males could be caused by mating status per se.

In a second model, we tested for effects of mating status and number of social fledglings on the probability of siring extra-pair fledglings. There was no significant random effect of male identity on the probability of a male siring at least one extra-pair fledgling (tested without fixed effects; $\chi^{2}=0.16, \mathrm{df}=1, p=0.69$ ). However, older males were more likely to sire at least one extra-pair fledgling (Table 2b) and the probability of siring at least one extra-pair fledgling differed between years (Table $2 b$ ). There was no additional significant effect of the number of social fledglings, mating status or tarsus length (Table $2 b$ ).

The number of social fledglings (with the only or primary female) also varied annually (Table $2 \mathrm{c}$ ), but was not affected by mating status, age or tarsus length (Table 2c). Older males were more likely to be polygynous (Table 2d), but the likelihood of polygyny did not differ 
Table 1 Summary of the different components of annual male reproductive success and their effects on the annual number of genetic fledglings sired by males in the study population

\begin{tabular}{|c|c|c|c|c|c|}
\hline Component & Average (SD) & Range & Effect (SE) & $\chi^{2 a}$ & $\%$ Total variance \\
\hline Nr. of social fledglings (with only or primary female) & $9.10(2.50)$ & $2-14$ & $0.88(0.01)$ & 4,247 & 26.9 \\
\hline Prop. of within-pair paternity (with only or primary female) & $0.89(0.19)$ & $0-1$ & $8.15(0.18)$ & 2,087 & 13.8 \\
\hline Nr. of extra-pair fledglings & $0.75(1.67)$ & $0-9$ & $0.98(0.02)$ & 2,348 & 15.4 \\
\hline Nr. of secondary fledglings & $0.74(2.31)$ & $0-11$ & $1.00(0.01)$ & 4,838 & 30.5 \\
\hline
\end{tabular}

Test statistics were calculated when entered simultaneously in the model, but see 'Methods' for the calculation of percentage of explained total variance

${ }^{\mathrm{a}}$ all $\mathrm{df}=1$, all $p<0.001$

Table 2 Summaries of models examining the interrelatedness between male reproductive components, while including the effects of year, age and body-size (tarsus length)

\begin{tabular}{|c|c|}
\hline Effect (SE) & $\chi^{2}$ \\
\hline
\end{tabular}

a. Dependent variable: proportion of within-pair paternity

Independent variable

Mating status

$-0.72(0.31)$

5.27

1

0.022

Non-significant variables

Nr. of extra-pair fledglings

$0.00(0.08)$

0.00

$0.04(0.05)$

0.59

Nr. of social fledglings

2007: $0.24(0.29)$ 2008: $0.32(0.34)$ 2009: $0.35(0.36)$

1.35

$0.32(0.25)$

1.64

$0.52(0.30)$

3.10

Tarsus length

extra-pair fledglings

b. Dependent variable:
Independent variable

Year $(2006=$ reference $)$

Age

Non-significant variables

Nr. of social fledglings

Mating status

$0.75(0.51)$

$0.19(0.47)$

Tarsus length

c. Dependent variable: number of social fledglings

Independent variable

$\begin{array}{rrr}9.98 & 3 & 0.019 \\ 16.82 & 1 & <0.001\end{array}$

$\begin{array}{lll}1.00 & 1 & 0.32\end{array}$

$\begin{array}{lll}2.17 & 1 & 0.14\end{array}$

$\begin{array}{lll}0.17 & 1 & 0.68\end{array}$

Year $(2006=$ reference $)$

2007: -0.04 (0.07); 2008: 0.24 (0.07); 2009: 0.19 (0.07)

$-0.05(0.07)$

Mating status

$0.02(0.05)$

Age

$-0.04(0.06)$

d. Dependent variable: mating status

Independent variable

Age

$1.03(0.44)$

2007: -0.01 (0.60); 2008 : 0.74 (0.57); 2009: -0.27 (0.74)

$-0.32(0.51)$

Non-significant variables

Year $(2006=$ reference $)$

Tarsus length

$<0.001$

$\begin{array}{lll}0.47 & 1 & 0.49\end{array}$

$\begin{array}{lll}0.14 & 1 & 0.71\end{array}$

$\begin{array}{lll}0.50 & 1 & 0.48\end{array}$

Final models were obtained by stepwise backwards elimination of non-significant variables. Statistics for non-significant variables were derived from entry back into the final model 
between years and was not affected by the male's tarsus length (Table 2d).

Effects of age and polygyny on annual male reproductive success

Mating status had the greatest effect on variance in annual genetic reproductive success (see Table 1) but was also associated with male age (see Table $2 \mathrm{~d}$ ), so we modelled the effects of these variables on reproductive success. This revealed that both mating status and age contributed independently to reproductive success (in the same model; age: effect $(\mathrm{SE})=+1.44(0.56), \chi^{2}=6.65, \mathrm{df}=1, p=0.010$; mating status: effect $(\mathrm{SE})=+5.11(0.80), \chi^{2}=40.87, \mathrm{df}=$ $1, p<0.001)$. However, adding the interaction between age and mating status to the model revealed that the effect of mating status on reproductive success was significantly greater for older males, compared to first-year males (Fig. 2a, age $\times$ mating status: effect $(\mathrm{SE})=+3.78(1.60)$,
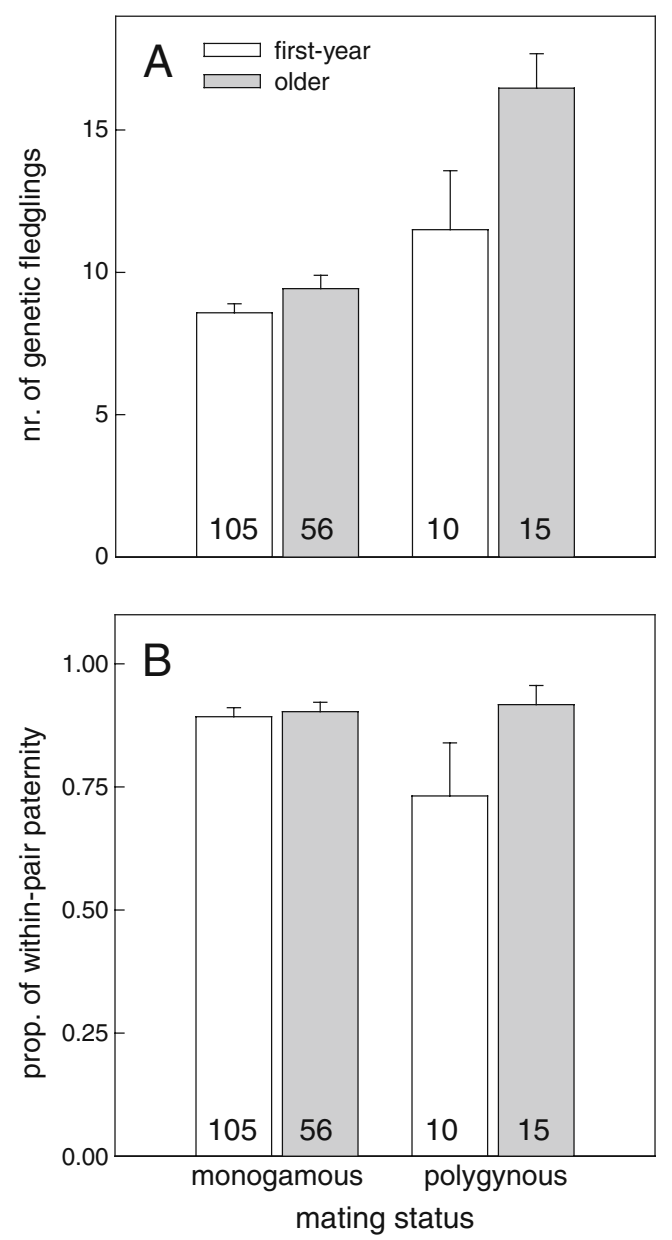

Fig. 2 The effect of male mating status and age on a the mean $( \pm \mathrm{SE})$ annual number of fledglings sired by breeding males and $\mathbf{b}$ the mean $( \pm \mathrm{SE})$ proportion of within-pair paternity with the (primary) social female. Values within the bars represent the number of males per category $\left.\chi^{2}=5.58, \mathrm{df}=1, p=0.018\right)$. This could not be attributed to an interaction effect between age and mating status on the number of social fledglings $\left(\chi^{2}=0.25, \mathrm{df}=1, p=0.62\right)$ or on the probability of siring extra-pair fledglings $\left(\chi^{2}=0.04\right.$, $\mathrm{df}=1, p=0.84$ ). Instead, the pattern was explained by the interaction effect between age and mating status on the proportion of WPP, indicating that older polygynous males were less cuckolded than first-year polygynous males with their primary female (Fig. 2b, age $\times$ polygyny: logistic effect (SE) $\left.=+1.65(0.71), \chi^{2}=5.35, \mathrm{df}=1, p=0.021\right)$. The number of social fledglings produced by secondary females was not dependent on male age $\left(\chi^{2}=0.83, \mathrm{df}=1\right.$, $p=0.36$ ), but the proportion of WPP with the secondary female was also greater for older males, compared to firstyear males (logistic effect $(\mathrm{SE})=+1.24(0.34), \chi^{2}=13.59$, $\mathrm{df}=1, p<0.001)$. Regardless of age, the proportion of WPP with the primary female was positively related to the proportion of WPP with the secondary female (logistic effect $\left.(\mathrm{SE})=+3.70(0.72), \chi^{2}=26.68, \mathrm{df}=1, p<0.001\right)$, indicating that a male's share of WPP was not only consistent between years but also across different females within the same year.

\section{Discussion}

We found that both the occurrence of EPP and polygyny considerably increased variance in reproductive success among male blue tits, thus enhancing the potential for sexual selection. However, our estimate of variance in genetic reproductive success was not based on complete data. We could not assign paternity to all extra-pair fledglings, implying that paternity was gained by nonbreeding males, males who's nests failed before capture and/or males from outside the study area. Moreover, males from within the study population are also likely to have sired fledglings outside the study area. The effect of this missing information on our estimates remains speculative, but in general, the effect of EPP on variance in male reproductive success is predicted to decline with the proportion of offspring for which paternity is known (Freeman-Gallant et al. 2005). In contrast, the effect of mating status on variance in reproductive success is likely to have been an underestimate given that some males acquired two females, suggesting that others failed to pair at all, as the sex ratio at hatching generally does not deviate from parity in blue tits (e.g. Korsten et al. 2006; Delhey et al. 2007a). However, if polygyny results from a shortage of males because of lower survival of males after hatching, rather than differences in male mating success, this underestimation of variance in reproductive success would be attributable to natural selection and not sexual selection. 
More informative may be the patterns of covariance between securing paternity with the (primary) social female and gaining additional paternity, either through extra-pair fertilisations or by attracting a second social female. Since the proportion of WPP in the social brood did not decline with the number of extra-pair fledglings gained at other nests, EPP will increase the variance in male reproductive success as the subset of males that achieve these extra-pair fertilisations have a higher overall reproductive success, at the expense of males that lose paternity. However, the absence of positive covariance between these reproductive strategies also suggests that the potential for sexual selection is restricted by the fact that successful extra-pair sires are just as frequently cuckolded as other males. Therefore, if all females prefer to copulate with males that have particular characteristics, this preference is not sufficiently strong to limit WPP loss among these same males. Such a pattern may arise if the reduced effort by preferred males to secure WPP (e.g. mate guarding effort) in order to invest more in gaining EPP, is counterbalanced by a lower incentive for their social females to engage in EPC (Kokko and Morrell 2005). However, non-directional female choice for extra-pair males may be a more likely explanation, as predicted by fertility insurance or compatibility explanations for EPC.

Indeed first-year polygynous males that had significantly greater genetic reproductive success than first-year monogamous males (Fig. 2a, effect (SE) $=+3.02(1.19), \chi^{2}=6.46$, $\mathrm{df}=1, p=0.011)$ were cuckolded more often despite their success at attracting a second female. This is not uncommon in birds, as a review of 21 empirical studies based on 17 species reveals that polygynous males lost greater WPP compared to monogamous males in seven species, while only in one species was the reverse pattern reported (Table 3). Moreover, some of the nine studies that found no effect may have suffered from a lack of power. In the two species where one study reports a negative effect of polygyny on WPP while a second reveals no effect, the negative effect was reported by the study with the greater sample size (pied flycatcher Ficedula hypoleuca; Lifjeld et al. 1991; Lubjuhn et al. 2000, blue tit; Kempenaers et al. 1995, this study). In blue tits, polygynous males generally fledge more offspring without incurring a reduced likelihood of survival to the next breeding season (Dhondt 1987; Kempenaers 1994; Vedder et al. unpublished results). Hence, average fitness of polygynous males is probably

Table 3 Summary of studies that have tested for an effect of mating status on the proportion of within-pair paternity (WPP) in facultatively polygynous bird species

\begin{tabular}{|c|c|c|}
\hline Species & Effect & Study \\
\hline Black-browed reed warbler (Acrocephalus bistrigiceps) & Negative & (Hamao and Saito 2005) \\
\hline Blue tit (Cyanistes caeruleus) & No effect & (Kempenaers et al. 1995) \\
\hline Bobolink (Dolichonyx oryzivorus) & No effect & (Bollinger and Gavin 1991) \\
\hline Corn bunting (Miliaria calandra) & No effect & (Hartley et al. 1993) \\
\hline Dusky warbler (Phylloscopus fuscatus) & No effect & (Forstmeier 2003) \\
\hline European starling (Sturnus vulgaris) & No effect & (Pinxten et al. 1993) \\
\hline European starling (Sturnus vulgaris) & No effect & (Smith and Sandell 1998) \\
\hline European starling (Sturnus vulgaris) & No effect & (Smith and Vonschantz 1993) \\
\hline Great reed warbler (Acrocephalus arundinaceus) & No effect & (Hasselquist et al. 1995) \\
\hline House wren (Troglodytes eadon) & Negative & (Soukup and Thompson 1997) \\
\hline House wren (Troglodytes eadon) & Negative & (Poirier et al. 2004) \\
\hline Indigo bunting (Passerina cyanea) & No effect & (Westneat 1987) \\
\hline Pied flycatcher (Ficedula hypoleuca) & Negative & (Lubjuhn et al. 2000) \\
\hline Pied flycatcher (Ficedula hypoleuca) & No effect & (Lifjeld et al. 1991) \\
\hline Red-winged blackbird (Agelaius phoeniceus) & No effect & (Westneat 1993) \\
\hline Rock sparrow (Petronia petronia) & Negative & (Pilastro et al. 2002) \\
\hline Savannah sparrow (Passerculus sandwichensis) & Positive & (Freeman-Gallant 1997) \\
\hline Southwestern willow flycatcher (Empidonax traillii extimus) & No effect & (Pearson et al. 2006) \\
\hline Spotless starling (Sturnus unicolor) & Negative & (Cordero et al. 2003) \\
\hline Tree swallow (Tachycineta bicolor) & Negative & (Dunn and Robertson 1993) \\
\hline Willow ptarmigan (Lagopus lagopus) & Negative & (Freeland et al. 1995) \\
\hline
\end{tabular}

A negative effect indicates a significantly lower proportion of WPP for polygynous males, no effect indicates the lack of a significant difference in WPP between monogamous and polygynous males, while a positive effect indicates that polygynous males had a significantly greater proportion of WPP 
considerably higher than for monogamous males. In fact, in this study the seven males that fledged the most offspring in a single season were all polygynous, each siring at least 20 fledglings (Fig. 1b). Although these secondary offspring may be of lower quality (Bjorklund 1996) because they receive little or no paternal investment and, by definition, fledge later in the season than offspring of the primary female, it is unlikely that any reduction in offspring quality would counter the male fitness benefits of attracting a secondary female. Moreover, the proven ability of these males to attract a second social female implies that they are favoured by females. Hence, if the ability to become polygynous is heritable, females seeking 'good genes' through EPC should favour polygynous males (Weatherhead and Robertson 1979), regardless of whether they can assess polygyny per se or only the underlying traits that allow these males to become polygynous (Kokko et al. 2002; Huk and Winkel 2008). However, after correcting for age, polygynous males did not gain more EPP, while first-year polygynous males, in particular, suffered higher WPP loss. The heritability of polygyny is unknown for blue tits, and the findings from studies on other species have been equivocal. One study on pied flycatchers reports that sons from polygynous males, when raised with the primary female, were more likely to become polygynous and obtain greater lifetime reproductive success than sons from monogamous pairs (Huk and Winkel 2006), while in contrast, a study on collared flycatchers (Ficedula albicollis) found that sons of polygynous males were less likely to become polygynous, compared to sons from monogamous pairs (Gustafsson and Qvarnstrom 2006). In general, male traits closely linked to fitness are found to exhibit low heritability (e.g. Merila and Sheldon 2000; McCleery et al. 2004), which may constrain the scope for the 'good genes' explanation for female engagement in EPC.

Alternatively, females may seek copulations with genetically more compatible males to improve offspring quality (Jennions and Petrie 2000; Neff and Pitcher 2005). In this case, there would be no directional preference for heritable traits, and hence, it would be questionable to suggest that EPP increases the strength of sexual selection (Puurtinen et al. 2009). However, our finding that the loss of WPP was positively correlated among different females paired to the same male, either in the same or in a different breeding season, does not support the 'compatible genes' explanation, because it is unlikely that different social females would be equally (in) compatible with the same male.

Success at gaining EPP and becoming polygynous was positively related to age. Increased extra-pair success by older males is a frequent phenomenon in birds (e.g. Weatherhead and Boag 1995; Wetton et al. 1995; Richardson and Burke 1999; Johnsen et al. 2001; Schmoll et al. 2007), but little is known about why this pattern arises. Several possible explanations include (1) a female preference for more viable males, which, because of their higher survival probability, will be overrepresented among older males, (2) an increase in male EPC success with experience and (3) a female preference for more familiar males, which would favour older males. The first explanation is consistent with the 'good genes' hypothesis for EPC; however, we did not find a significant random effect of male identity on the probability of siring extra-pair fledglings. Moreover, in the subset of males for which we had data in both their first and second years $(n=15)$, there was a trend for individuals to sire more extra-pair fledglings in their second year (Wilcoxon signed-rank test, $Z=-1.83, p=0.068$ ). None of these males sired fewer extra-pair fledglings in their second year. This indicates that the greater success of older males is more likely to reflect improving performance with age, consistent with the benefits of experience or familiarity. Greater experience may also explain the increased share of WPP among older polygynous males compared to first-year polygynous males. Perhaps older males are more efficient at attracting a second female without compromising paternity with their first.

Overall, we suggest that our observations are most consistent with the fertility insurance explanation, or other unrecognised non-genetic benefits, for female engagement in EPC. If females copulate with extra-pair males regardless of their social male's phenotype, then males that are successful at gaining EPP or attracting secondary females would lose a similar or even greater proportion of paternity with their social (primary) female than unsuccessful males. Furthermore, the within male consistency of WPP loss across different females suggests that there may be genuine differences in within-pair fertilisation success between males. Combined with earlier work on blue tits suggesting that EPC takes place mainly before the start of egg laying (Magrath et al. 2009; Vedder et al. 2010b), a fertility insurance function would probably be the most parsimonious explanation. The main problem with this explanation is that strong selection against infertility is expected to generate little between-male variation in fertility. However, in contrast to the 'good genes' explanation, the causes of variation in fertility can be entirely environmentally induced. Since many factors (e.g. age, injury, health, copulation activity, nutritional status) can cause temporal infertility or reduced fertility in males (Sheldon 1994; Hasson and Stone 2009), the frequency of male functional infertility may be sufficient for females to benefit from copulating at least once with an extra pair male before she starts egg laying. Such a strategy among females would not exclude 'compatible genes' benefits, although these may be most evident in populations where in- or outbreeding depression is common among social mates. If 
there were sufficiently large differences between males in compatibility with the female, post-insemination fertilisation biases could favour the most compatible male (Griffith and Immler 2009), which may account for the heterozygosity benefits of EPC as reported by Foerster et al. (2003, 2006).

In sum, we find that both polygyny and EPP increase the potential for sexual selection in blue tits. However the absence of positive covariance between these two reproductive strategies suggests that females do not exhibit a directional preference for particular male phenotypes. Instead the observed patterns appear to be most consistent with a fertility insurance function of EPC or other possible direct benefits, although additional genetic benefits can not be excluded, and differential ability of males to gain paternity would still increase the potential for sexual selection.

Acknowledgements We would like to thank Rob Gordijn, Evelien Jongepier, Anna Harts, Daphne Niehoff, Peter Santema and Peter Wolfs for assistance with the fieldwork. We are also grateful to the 'Kraus-Groeneveld Stichting' for permission to work on 'De Vosbergen' estate. Permission for all procedures involving handling of blue tits was granted by the Animal Experiments Committee of the University of Groningen. Peter Korsten and Sandra Bouwhuis gave valuable comments on earlier versions of the manuscript. The research was financially supported by a Marie Curie International Incoming Fellowship to M.J.L. M. (CMIF1-CT-2005-008914) and grant numbers 028696 and 043318 to J.K., all of which are components of the European Community's Sixth Framework Programme.

Open Access This article is distributed under the terms of the Creative Commons Attribution Noncommercial License which permits any noncommercial use, distribution, and reproduction in any medium, provided the original author(s) and source are credited.

\section{References}

Arnold SJ, Wade MJ (1984) On the measurement of natural and sexual selection-theory. Evolution 38:709-719

Arnqvist G, Kirkpatrick M (2005) The evolution of infidelity in socially monogamous passerines: the strength of direct and indirect selection on extrapair copulation behavior in females. Am Nat 165:S26-S37

Bensch S, Price T, Kohn J (1997) Isolation and characterization of microsatellite loci in a Phylloscopus warbler. Mol Ecol 6:91-92

Bjorklund M (1996) The effect of male presence on nestling growth and fluctuating asymmetry in the blue tit. Condor 98:172-175

Bollinger EK, Gavin TA (1991) Patterns of extra-pair fertilizations in bobolinks. Behav Ecol Sociobiol 29:1-7

Charmantier A, Blondel J, Perret P, Lambrechts MM (2004) Do extrapair paternities provide genetic benefits for female blue tits Parus caeruleus? J Avian Biol 35:524-532

Chuang-Dobbs HC, Webster MS, Holmes RT (2001) The effectiveness of mate guarding by male black-throated blue warblers. Behav Ecol 12:541-546

Cordero PJ, Veiga JP, Moreno J, Parkin DT (2003) Extra-pair paternity in the facultatively polygynous spotless starling, Sturnus unicolor. Behav Ecol Sociobiol 54:1-6
Cramp S, Perrins CM (1993) Birds of the Western Palearctic, vol 7. Oxford University Press, Oxford

Dawson DA, Hanotte O, Greig C, Stewart IRK, Burke T (2000) Polymorphic microsatellites in the blue tit Parus caeruleus and their cross-species utility in 20 songbird families. Mol Ecol 9:1941-1944

Delhey K, Peters A, Johnsen A, Kempenaers B (2007a) Brood sex ratio and male UV ornamentation in blue tits (Cyanistes caeruleus): correlational evidence and an experimental test. Behav Ecol Sociobiol 61:853-862

Delhey K, Peters A, Johnsen A, Kempenaers B (2007b) Fertilization success and UV ornamentation in blue tits Cyanistes caeruleus: correlational and experimental evidence. Behav Ecol 18:399-409

Dhondt AA (1987) Reproduction and survival of polygynous and monogamous blue tit Parus caeruleus. Ibis 129:327-334

Dhondt AA, Eyckerman R, Schillemans J (1983) Polygyny by blue tits. Brit Birds 76:34-36

Double M, Cockburn A (2000) Pre-dawn infidelity: females control extra-pair mating in superb fairy-wrens. Proc R Soc Lond B 267:465-470

Dreiss AN, Silva N, Richard M, Moyen F, Thery M, Moller AP, Danchin E (2008) Condition-dependent genetic benefits of extrapair fertilization in female blue tits Cyanistes caeruleus. J Evol Biol 21:1814-1822

Dunn PO, Robertson RJ (1993) Extra-pair paternity in polygynous tree swallows. Anim Behav 45:231-239

Foerster K, Delhey K, Johnsen A, Lifjeld JT, Kempenaers B (2003) Females increase offspring heterozygosity and fitness through extra-pair matings. Nature 425:714-717

Foerster K, Valcu M, Johnsen A, Kempenaers B (2006) A spatial genetic structure and effects of relatedness on mate choice in a wild bird population. Mol Ecol 15:4555-4567

Forstmeier W (2003) Extra-pair paternity in the dusky warbler, Phylloscopus fuscatus: A test of the 'constrained female hypothesis'. Behaviour 140:1117-1134

Freeland JR, Hannon SJ, Dobush G, Boag PT (1995) Extra-pair paternity in willow ptarmigan broods - measuring costs of polygyny to males. Behav Ecol Sociobiol 36:349-355

Freeman-Gallant CR (1997) Extra-pair paternity in monogamous and polygynous savannah sparrows, Passerculus sandwichensis. Anim Behav 53:397-404

Freeman-Gallant CR, Wheelwright NT, Meiklejohn KE, States SL, Sollecito SV (2005) Little effect of extrapair paternity on the opportunity for sexual selection in savannah sparrows (Passerculus sandwichensis). Evolution 59:422-430

Gray EM (1996) Female control of offspring paternity in a western population of red-winged blackbirds (Agelaius phoeniceus). Behav Ecol Sociobiol 38:267-278

Griffith SC, Immler S (2009) Female infidelity and genetic compatibility in birds: the role of the genetically loaded raffle in understanding the function of extrapair paternity. J Avian Biol 40:97-101

Griffith SC, Stewart IRK, Dawson DA, Owens IPF, Burke T (1999) Contrasting levels of extra-pair paternity in mainland and island populations of the house sparrow (Passer domesticus): is there an 'island effect'? Biol J Linn Soc 68:303-316

Griffith SC, Owens IPF, Thuman KA (2002) Extra pair paternity in birds: a review of interspecific variation and adaptive function. Mol Ecol 11:2195-2212

Griffith SC, Barr I, Sheldon BC, Rowe LV, Burke T (2009) Egg patterning is not a reliable indicator of intraspecific brood parasitism in the blue tit Cyanistes caeruleus. J Avian Biol 40:337-341

Gustafsson L, Qvarnstrom A (2006) A test of the "sexy son" hypothesis: sons of polygynous collared flycatchers do not inherit their fathers' mating status. Am Nat 167:297-302 
Hamao S, Saito DS (2005) Extrapair fertilization in the black-browed reed warbler (Acrocephalus bistrigiceps): effects on mating status and nesting cycle of cuckolded and cuckolder males. Auk 122:1086-1096

Hartley IR, Shepherd M, Robson T, Burke T (1993) Reproductive success of polygynous male corn buntings (Miliaria calandra) as confirmed by Dna-fingerprinting. Behav Ecol 4:310-317

Hasselquist D, Bensch S, Vonschantz T (1995) Low-frequency of extrapair paternity in the polygynous great reed warbler, Acrocephalus arundinaceus. Behav Ecol 6:27-38

Hasson O, Stone L (2009) Male infertility, female fertility and extrapair copulations. Biol Rev 84:225-244

Huk T, Winkel W (2006) Polygyny and its fitness consequences for primary and secondary female pied flycatchers. Proc R Soc Lond B 273:1681-1688

Huk T, Winkel WG (2008) Testing the sexy son hypothesis-a research framework for empirical approaches. Behav Ecol $19: 456-461$

Hunt S, Bennett ATD, Cuthill IC, Griffiths R (1998) Blue tits are ultraviolet tits. Proc R Soc Lond B 265:451-455

Jennions MD, Petrie M (2000) Why do females mate multiply? A review of the genetic benefits. Biol Rev 75:21-64

Johnsen A, Lifjeld JT, Andersson S, Ornborg J, Amundsen T (2001) Male characteristics and fertilisation success in bluethroats. Behaviour 138:1371-1390

Kalinowski ST, Taper ML, Marshall TC (2007) Revising how the computer program CERVUS accommodates genotyping error increases success in paternity assignment. Mol Ecol 16:10991106

Kempenaers B (1994) Polygyny in the blue tit-unbalanced sex-ratio and female aggression restrict mate choice. Anim Behav 47:943957

Kempenaers B, Verheyen GR, Vandenbroeck M, Burke T, Vanbroeckhoven C, Dhondt AA (1992) Extra-pair paternity results from female preference for high-quality males in the blue tit. Nature 357:494-496

Kempenaers B, Verheyen GR, Dhondt AA (1995) Mate guarding and copulation behavior in monogamous and polygynous blue titsdo males follow a best-of-a-bad-job strategy. Behav Ecol Sociobiol 36:33-42

Kempenaers B, Adriaensen F, vanNoordwijk AJ, Dhondt AA (1996) Genetic similarity, inbreeding and hatching failure in blue tits: Are unhatched eggs infertile? Proc R Soc Lond B 263:179-185

Kempenaers B, Verheyren GR, Dhondt AA (1997) Extrapair paternity in the blue tit (Parus caeruleus): female choice, male characteristics, and offspring quality. Behav Ecol 8:481-492

Kirkpatrick M, Price T, Arnold SJ (1990) The Darwin-Fisher Theory of sexual selection in monogamous birds. Evolution 44:180193

Kokko H, Morrell LJ (2005) Mate guarding, male attractiveness, and paternity under social monogamy. Behav Ecol 16:724-731

Kokko H, Brooks R, McNamara JM, Houston AI (2002) The sexual selection continuum. Proc R Soc Lond B 269:1331-1340

Korsten P, Lessells CM, Mateman AC, van der Velde M, Komdeur J (2006) Primary sex ratio adjustment to experimentally reduced male UV attractiveness in blue tits. Behav Ecol 17:539-546

Krokene C, Rigstad K, Dale M, Lifjeld JT (1998) The function of extrapair paternity in blue tits and great tits: good genes or fertility insurance? Behav Ecol 9:649-656

Leech DI, Hartley IR, Stewart IRK, Griffith SC, Burke T (2001) No effect of parental quality or extrapair paternity on brood sex ratio in the blue tit (Parus caeruleus). Behav Ecol 12:674-680

Lifjeld JT, Slagsvold T, Lampe HM (1991) Low-frequency of extrapair paternity in pied flycatchers revealed by Dna fingerprinting. Behav Ecol Sociobiol 29:95-101
Lubjuhn T, Winkel W, Epplen JT, Brun J (2000) Reproductive success of monogamous and polygynous pied flycatchers (Ficedula hypoleuca). Behav Ecol Sociobiol 48:12-17

Magrath MJL, Vedder O, van der Velde M, Komdeur J (2009) Maternal effects contribute to the superior performance of extrapair offspring. Curr Biol 19:792-797

McCleery RH, Pettifor RA, Armbruster P, Meyer K, Sheldon BC, Perrins CM (2004) Components of variance underlying fitness in a natural population of the great tit Parus major. Am Nat 164: E62-E72

Merila J, Sheldon BC (2000) Lifetime reproductive success and heritability in nature. Am Nat 155:301-310

Moller AP, Birkhead TR (1994) The evolution of plumage brightness in birds is related to extrapair paternity. Evolution 48:1089-1100

Neff BD, Pitcher TE (2005) Genetic quality and sexual selection: an integrated framework for good genes and compatible genes. Mol Ecol 14:19-38

Owens IPF, Hartley IR (1998) Sexual dimorphism in birds: why are there so many different forms of dimorphism? Proc R Soc Lond B 265:397-407

Pearson T, Whitfield MJ, Theimer TC, Keim P (2006) Polygyny and extra-pair paternity in a population of Southwestern willow flycatchers. Condor 108:571-578

Pilastro A, Griggio M, Biddau L, Mingozzi T (2002) Extrapair paternity as a cost of polygyny in the rock sparrow: behavioural and genetic evidence of the 'trade-off' hypothesis. Anim Behav 63:967-974

Pinxten R, Hanotte O, Eens M, Verheyen RF, Dhondt AA, Burke T (1993) Extra-pair paternity and intraspecific brood parasitism in the European starling, Sturnus vulgaris - evidence from Dna fingerprinting. Anim Behav 45:795-809

Poirier NE, Whittingham LA, Dunn PO (2004) Males achieve greater reproductive success through multiple broods, than through extrapair mating in house wrens. Anim Behav 67:1109-1116

Puurtinen M, Ketola T, Kotiaho JS (2009) The good-genes and compatible-genes benefits of mate choice. Am Nat 174:741-752

Rasbash J, Steele F, Browne W, Prosser B (2004) A user's guide to MLwiN version 2.0. Institute of Education, London

Richardson DS, Burke T (1999) Extra-pair paternity in relation to male age in Bullock's orioles. Mol Ecol 8:2115-2126

Schmoll T, Mund V, etrich-Bischoff V, Winkel W, Lubjuhn T (2007) Male age predicts extrapair and total fertilization success in the socially monogamous coal tit. Behav Ecol 18:1073-1081

Sheldon BC (1994) Male phenotype, fertility, and the pursuit of extrapair copulations by female birds. Proc R Soc Lond B 257:25-30

Sheldon BC, Ellegren H (1999) Sexual selection resulting from extrapair paternity in collared flycatchers. Anim Behav 57:285298

Smith HG, Sandell MI (1998) Intersexual competition in a polygynous mating system. Oikos 83:484-495

Smith HG, Vonschantz T (1993) Extra-pair paternity in the European starling - the effect of polygyny. Condor 95:1006-1015

Soukup SS, Thompson CF (1997) Social mating system affects the frequency of extra-pair paternity in house wrens. Anim Behav 54:1089-1105

Svensson L (1992) Identification guide to European passerines. Märstatryck, Stockholm

Vedder O, Kingma SA, von Engelhardt N, Korsten P, Groothuis TGG, Komdeur J (2007) Conspecific brood parasitism and egg quality in blue tits Cyanistes caeruleus. J Avian Biol 38:625-629

Vedder O, Komdeur J, van der Velde M, Magrath MJL (2010a) Conclusive evidence for conspecific brood parasitism in the blue tit Cyanistes caeruleus: a reply to Griffith et al. J Avian Biol 41:348-349 
Vedder O, Magrath MJL, Harts AMF, Schut E, van der Velde M, Komdeur J (2010b) Reduced extrapair paternity in response to experimental stimulation of earlier incubation onset in blue tits. Behav Ecol 21:9-15

Wade MJ, Arnold SJ (1980) The intensity of sexual selection in relation to male sexual-behavior, female choice, and sperm precedence. Anim Behav 28:446-461

Walsh PS, Metzger DA, Higuchi R (1991) Chelex-100 as a medium for simple extraction of Dna for Pcr-based typing from forensic material. Biotechniques 10:506-513

Weatherhead PJ, Boag PT (1995) Pair and extra-pair mating success relative to male quality in red-winged blackbirds. Behav Ecol Sociobiol 37:81-91

Weatherhead PJ, Robertson RJ (1979) Offspring quality and the polygyny threshold - sexy son hypothesis. Am Nat 113:201-208

Webster MS, PruettJones S, Westneat DF, Arnold SJ (1995) Measuring the effects of pairing success, extra-pair copulations and mate quality on the opportunity for sexual selection. Evolution 49:1147-1157

Westneat DF (1987) Extra-pair fertilizations in a predominantly monogamous bird-genetic-evidence. Anim Behav 35:877-886

Westneat DF (1993) Polygyny and extrapair fertilizations in Eastern red-winged blackbirds (Agelaius phoeniceus). Behav Ecol 4:49-60

Westneat DF, Stewart IRK (2003) Extra-pair paternity in birds: causes, correlates, and conflict. Ann Rev Ecol Evol Syst 34:365-396

Wetton JH, Burke T, Parkin DT, Cairns E (1995) Single-locus Dnafingerprinting reveals that male reproductive success increases with age through extra-pair paternity in the house sparrow (Passer domesticus). Proc R Soc Lond B 260:91-98

Whittingham LA, Dunn PO (2005) Effects of extra-pair and within-pair reproductive success on the opportunity for selection in birds. Behav Ecol 16:138-144 